\title{
Advancing a Typology of Media Content: Analysis of a Literary Journalism Story
}

\section{Zhongshi Guo*}

Baptist University, Kowloon, Hong Kong

"There is an interest in that which is hidden and which the visible does not show us. This interest can take the form of a quite intense feeling, a sort of conflict, one might say, between the visible that is hidden and the visible that is present.'

\section{--Belgian surrealist painter René Magritte}

The way stories are told to the public in any society, even the most draconian ones, always leaves some room for trivia non grata to beholders in the ruling authorities. Seditious messages passing for praises do find their way into public discourse to rub power holders the wrong way. Since symbolic representation of reality makes it impossible for any text to be seamlessly closed, linguistic cracks and loopholes open up endless possibilities for the imaginative writer with a hidden political agenda in authoritarian societies.

Where broad social effects count, mass media are indisputably the dominant platform on which orthodoxy and heresy, culture and counter-culture, meaning and mock meaning are locked in a constant battle of wits for publicity, recognition, and legitimacy. To initiators of dissent, entry into public discourse alone is sufficient cause for celebration. Once there, all the meticulous designs to contradict, insult, humiliate, ridicule, and enrage, without seeming to do so, would have paid off.

In China, the official mass media, which is to say all mass media, have inadvertently been offering that service to contenders of the mainstream ideology ever since the late party chief Deng Xiaoping masterminded the reform agenda more than three decades ago [1]. With control over political content gradually yielding to market imperatives, a new pattern of interaction has emerged in the symbolic negotiations between the state and the country's intelligentsia. In an unprecedented move toward polarization, radical reformists and Maoist fundamentalists alike are delivering punches, sometimes literally at sites of physical contact, to one another and both to representatives of incumbent administrations. They fight, not so much for expansion of influence as to make sure that they get to keep their own turf, their crowd of niche constituents, and their share of the social capital.

In the process, reportage has always been a much coveted, and indeed revered, venue for warring camps to expound their views, if only implicitly. In the political context of life in China, some of the main charms of literary journalism are its license for plausible speculation, its soft novelette style and its reputation for credibility. Only established journalists and writers (are allowed to) attempt it. Which brings us to the theme of the current study. In our analysis of literature journalism in China, we are primarily concerned with how complex confrontations among vested interests spanning China's ideological spectrum come to be represented in the official single-voice mass media. More specifically: how is resentment against the reigning socio-political system tactically written into the text of reportage behind the façade of legitimacy? To address this issue, we begin with culling what others have said in this regard and follow it up with the specification of a model of content typology. The remaining section of this essay is devoted to the case analysis of a specific piece of reportage.

\section{Contestation in Political Discourse}

What motivated this research was an observation that the content of any given media writing could be imbued with anti-mainstream ideas. This is so mainly because contributors to the content include those who harbor ideas that are likely to incur displeasure from authorities. However, making these ideas public or publishable requires that they be presented in non-offending terms, acceptable the target of the offence in the first place. Nowhere perhaps is the intensity of such contestation in political discourse more prominent than in China's media system today.

Previous research on China's media reform has produced an amalgam of insights, although the most interesting, in our view, is the part concerning conflicts and contradictions [2-6]. A survey of relevant literature generates a strong impression of two opposing views. The first sees market and political control as irreconcilable alternatives $[7,8]$ and the second is optimistic about co-optation whereby the party organ press tactfully absorbs mass-appeal media's market success through conglomeration [9].

Either way, media organizations are duty-bound [2] to make a choice, or "take a line," as the inside vernacular has it, between commitments to intense political discourse versus meretricious infotainment and to contestation with core ideology versus advocacy of it $[10,11]$. Ironical as it seems, the unified mouthpiece role of the whole of journalism in China belies subtle allegiances by individual media outlets, not to mention journalists, to specific ideological stances on the left-right continuum, especially for the print press [12]. The more extreme such political siding is, the more readily identifiable its bias is to the audience, and the more intense the degree of contestation.

Research has shown that newspapers perceived to adopt a rightwing slant enjoy a larger circulation among young and educated readers than their left-wing counterparts, even though both are critical of the ruling elite and run the same risks of disciplinary actions [13]. In between, media that plea "no contest" have in effect chosen the safe haven of market and, in so doing, claimed immunity from political sanctions. Contestation in China's public discourse, therefore, is a predictable and structured behavior. It positions media content and fixes audience expectations [14].

*Corresponding author: Zhongshi Guo, Hong Kong Baptist University, Kowloon, Hong Kong, Tel: 852-3411 7400; E-mail: quo@hkbu.edu.hk

Received October 24, 2014; Accepted November 27, 2014; Published December 04, 2015

Citation: Guo Z (2014) Advancing a Typology of Media Content: Analysis of a Literary Journalism Story. J Mass Communicat Journalism 5: 237. doi:10.4172/2165-7912.1000237

Copyright: (c) 2014 Guo Z. This is an open-access article distributed under the terms of the Creative Commons Attribution License, which permits unrestricted use, distribution, and reproduction in any medium, provided the original author and source are credited. 


\section{A Typology of Media Content}

Based on our observations and guided by previous research, we propose a model of analysis to organize the massively different types of media messages into a coherent whole and herd them under the general rubric of "typology of media content." This typology maps stories with their ideological underpinnings and reveals the intriguing connections between text and subtext. If we were to consider China's media message system, not as a synchronized voice of celebration, but as a left-right scale of advocacies and oppositions, then the very nature of contestation with core ideology is sufficient temptation for journalists to negotiate and test the limits of legitimate discourse. However one sees it, the space in the country's traditional media now open to anything between criticisms and stress calls is unparalleled in the history of the communist rule.

At both ends of this continuum are small groups of media outlets, really people who run them, whose mission it is to take issues with domination which, at present, revolves around the idea of party controlled market economy. In between the two extremes is a vast terrain of seemingly depoliticized realm of discourse that caters to the broadest of audiences. Figure 1 gives a graphic rendition of the structure of this media content typology. The oval space, in the shape of an egg, wrapped within solid lines is the entirety of public discourse. The center or the "yolk" represents the core value system and dogmatic inculcation emitting from both adherence to a tradition of justifying domination and a concurrent need to unify minds toward the paramount goals of harmony. In practically all nations and societies, content of the core includes such barest necessities as patriotism, national interest, territorial integrity, legitimacy of the current government, and the overarching religion, where applicable.

To build up centripetal force, the core is given the highest order in the public sphere, representing the fundamental party and state principles, rituals, beliefs, principles, and doctrines as well as their dissemination and interpretation with expectations of full compliance [15]. Reflected in content are familiar legitimizing devices of chanting the party clichés, usually corroborated with marginalizing and delegitimizing opposition and dissent or silence treatment of sensitive issues. This is the hardened part of the media content that is remarkably enduring, resistant to challenge and change, and serves the Gramscian [16] notion of firm defense against internal and external pressure.

The thin space between the two solid outside rings (the outer one being the "egg shell") symbolizes challenges to the order established in the core, or "breach of expectancies" as described by Hebdige [17]. Instead of posing as centrifugal forces, journalists embed oppositional views, dissent and tacit rejection in the form of alternative frames [18]. They impose interpretive structures on stories [19], create context [20], and invent imaginative narrative strategies to expose, analyze, question, comment or otherwise sabotage the existing social order, system biases, institutional malpractices, and flipsides of policies.

Political discourse intensifies rather than weakens in the process, culminating in the contestation between core ideology and people of "critical intelligence" [21] or those belonging to a "network of antidiscipline" [22]. This shell-core contestation is a powerful conditioner for political discourse. And the dynamics of the model is expressed in the frequent contraction or expansion of the shell in response to the loosening or tightening of the core. Interestingly, both the nostalgic leftists reminiscent of the equalitarian Mao era and the impatient rightist liberals eager to materialize the free-press and every-vote-count

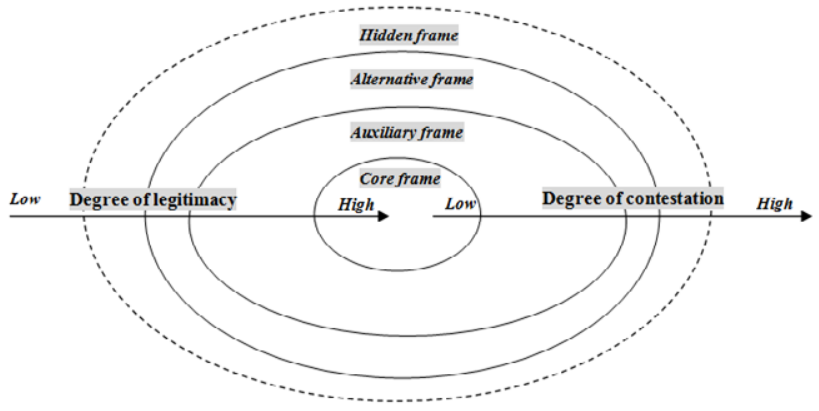

Figure 1: A typology of media content in China.

sort of democracy have an equal footing in this discourse (Figure 1).

Representatives of both voices (e.g., the liberal Southern Weekend and the conservative Truth Seeking) have learned their lessons the hard way, having experienced editorial board reshuffling imposed by an enraged state. Their proportions are small, but the intellectuals they claim to represent are an articulate and inflammatory force to be reckoned with. Occasional outbursts of anger notwithstanding, authorities have largely condoned and accepted the existence of moderate dissent as the evil twin of economic plurality [23]. The area between the solid and dotted lines is a fairly extensive and elastic domain of social discourse kept outside of mass media. This space is beyond what Hallin [24] called the sphere of legitimate discourse because its content is a shared critique of domination filled with bitter grievances, irreverence, vile obscenities, sabotaging opinions and threats directed at the ruling authorities. They are kept alive mainly in interpersonal settings and thrive through social media.

In his seminal work on hidden transcript, James Scott [25] scrutinized the process and methods by which subordinates rack their brains to reveal the concealed and express the inexpressible, while going to great lengths to avoid violating the accepted rules of public discourse. Although the setting is largely interpersonal, the theoretical structure provides important revelations for the probe of the shell-core conflict in the mass media context. In a way, the sort of performances put up by individuals in this context are akin to Goffman's [26] notion of "front region" and "back region" where, for any given individuals or institutions, resistant behavior can comfortably coexist with submissive activity, depending on whether one is in the presence or absence of domination.

Rather than bothering with the futile attempt to detect the author's intentions or assess the realness of a show on a public stage, the morale of the story here is this: since resistance by the dominated must be made known to the dominators even in the most banal practices of everyday life, one needs to look no further than what is actually said. And because of the belief that ulterior motives hide behind what gets said, reading of such texts demands social knowledge, ability to critically appraise hidden messages and a profound respect for fine prints, innuendos, Geertzian winks [3], so to speak, and mixed signals.

In contrast, the area outside of the core (the "egg white") covers the bulk of media content and is characterized by the ostensibly depoliticized discourse, which takes the form of blatant glorification of consumerism and vulgarism. Anti-politics, to use Moody's [27] term, "has permeated the general culture since the onset of reform". The ascendancy of materialistic pursuit in virtually every corner of social 
life has intimately tied consumers to a set of values and established universe of discourse, both pleasant and appealing [28]. For any given media or content type, compliance is but a small price to pay to prevent this huge commercial goldmine from turning into political quicksand.

The rise of the middle class, with its special purchasing power, needs, consumption patterns, and distaste for political activism, adds a new dimension in China's social configuration [29] and exacerbates the urgency for minimizing media's political content in favor of consumerism [30]. Their reticence and apathy should not be taken at face value. It is detachment by choice [31,32], a rejection of "corruption, cruelty, and hypocrisy that politics entails" [27]. A marginal political group seeking refuge from the coercive state has become what De Certeau [22] called "the silent majority". With state endorsement and huge profits to be gained, mass media have facilitated and responded to the trend vehemently. Acting as a buffer zone between the core-shell clashes, the auxiliary frame promotes and sugarcoats the core with entertainment, infotainment, parochial angles, entrepreneurship, affordable luxury, and human interest. As such, the media have reconstructed images of success and redefined ideals of self-actualization with their field of vision mainly confined to middle-class political agnostics.

Each of the four parts of the media content typology model is conceptually independent. They are connected by three indexes from core to periphery: 1) the degree of legitimacy (or approved authority) tapers off, as 2) the degree of contestation intensifies, and 3 ) susceptibility to change increases. This model allows unconstrained variance in the content even though its structure remains relatively invariant across time and space.

To demonstrate that the typology model presented here, which pits rule against resistance, exercise of power against experience of life, and the said against the unsaid, provides a meaningful perspective for theoretical understandings of the encoding and decoding process, we shall now proceed, in the section below, to microscopically examine an exemplar piece of literary journalism, dissecting it, where necessary, to its smallest units in the hope to show that the space for rhetoric play of words is without borders.

\section{Reportage Case Study: The Death of a Champion Weightlifter}

At the time of its first publication in June 2003, the long-form feature "The Death of a Champion Weightlifter" stirred up an instant sensation. The very headline boded ill with an unflattering undertone suggesting foul play. Reasons for public interest in this story might have left much to imagination but little to surprise: a) The story was carried on Southern Weekend, bearer of the torch of democracy at the forefront of China's most liberal press; b) the story was about the decay of the country's sports management system that was popularly seen not just as the root of many evils in the games arena, although the article has surely suggested that, but more importantly, as an allusion to practically all other, similar sub-systems of the rusty state machine (housing and medical problems come to mind); and c) throughout the article, a host of rhetorical skills were employed to counter the official propaganda without appearing to do so and to elicit a grin-and-bear-it kind of response from the knowing reader.

To quote the writer of the story, Li Haipeng who was barely over 30 but already a doyen at literary journalism back then, "the ultimate goal of journalism is to about public interest, freedom of thought, and mass enlightenment" [33]. The three key words in this brief mission statement, public interest, freedom of thought, and mass enlightenment, when applied to the sensitive domain of journalism, are typically frowned upon by the authorities because their idealistic surface meanings speak to their absence in reality.

The story follows a simple line: the last four years of a national weightlifting champion who suffered a slow and painful death from sleep disorder that could have easily been averted if he had been treated with proper medical attention and respect and if he and his family were not living in stark poverty. The story opens with a short paragraph that contains all the key messages and assumptions. It sets the tone of a chain of lurking accusations:

On account of Temporary Respiratory Distress Syndrome (TRDS) during sleep, years of living in poverty and bad habits, the 160-kilogram Cai Li vomited himself into a stupor and died without dignity. In the last four years of his life, he worked as a doorman at a local sports organization. On the day of his death, his whole family had a total of 300 yuan in cash.

The three rather plain sentences of factual account in the lead invite questions even from an undiscerning reader: why did a national champion have to lead a poverty-stricken life (RMB $¥ 300$ yuan is worth about US\$45); what had happened to warrant the claim that a person died without dignity in China; why couldn't the national champion, being what he was, find a more decent job or, for example, a career in coaching; how come he was not covered by any forms of insurance or social welfare; at what point and how was he "abandoned" by the sports institution he had been in service with since he was a little kid; how much formal education did he receive to make him a competent worker in the labor market outside of weightlifting; what would friends, relatives, fellow sportsmen, and neighbors think of his plight; what level of awkward humiliation that this Hercules of a man who once was sitting on the laurel of national fame had to endure in the years before his death; how individual was this particular case in the larger system. The list goes on.

Questions like these, each valid in its own merit, clash head-on with the dominant rhetoric found in the core message systems on the mainstream media. They are testimony to some of the most profound political, economic, social, and cultural problems plaguing Chinese society today, although none of them is actually stated and most of them off limits in the official discourse. The writer implies resistant aspirations, but uses caution to place them under the fragile sheet of reality description, as if to make sure that they pop up at the slightest hint. Here, the value of the subtext lies in its capacity for reconfiguration as text in the mind of the readers. Viewed in this light, questions, not the answers, which are directed toward systemic malfunctioning, are themselves acts of subversion and the goal of contestation.

In what Foucault [34] called a "heterogeneous ensemble" consisting of a mixture of individuals and institutions, rituals and norms, laws and science, the subject of attention is turned to the discursive exercise that bridges the said and the unsaid "to identify in this apparatus... precisely the nature of the connection that can exist between these heterogeneous elements". As a result, the power of suggestion does its job, partly by having its bitter active ingredients sweetened with legitimacy, and partly by allowing sufficient room for extrapolation or any stretch of imagination about the ultimate source of the ordeals in life of ordinary people. To avoid raising the eye brows of the wrong people when prodding the system, the writer of the weightlifter story resorted to a series of narrative tactics to bring to afore the towering presence of what is absent.

Repetition as breach of linguistic conventions 
Nothing brings poverty home more gnawingly than its countless little manifestations in concrete circumstances, particularly so when disasters (or diseases in this case) hit, which may be why when it comes to money the writer refuses to let any of the details slip through the 33-paragraph story. No big fuss was ever made about how low life could be reduced to for people living at the bottom of the social stratum, just figures, precise and heart wrenching figures, repeated multiple times (words in brackets added by the writer of this paper):

Paragraph 1: On the day of his death, his whole family had a total of 300 yuan in cash.

Paragraph 6: She (the wife) could afford to eat buns that sell 3 for one yuan (a cheeseburger costs 10 yuan at McDonald's)... His father bought the vegetables yesterday right before the wet market closed (when price would usually drop), for a total of 4.7 yuan.

Paragraph 15 He pocketed the 20 yuan from Mom and the 100 yuan from Pop as taxi fare... and headed for the hospital. Eight hours later, he really died (He joked about it earlier).

Paragraph 18: She (the wife) did a quick math, 300 yuan. That's all they had in the whole family.

Paragraph 19: He (the father) thought for a while and decided to borrow 300 yuan.

Paragraph 20: He (the father) stood in the hall, with the 300 yuan in hand, not sure who to turn to next.

Paragraph 21: They couldn't move back, because the 350 yuan per square meter compensation money was too much for local residents who wanted to move back.

Paragraph 23: $\mathrm{He}$ (the father) borrowed another 100 yuan... (A kind lady from the neighborhood) loaned him 400 yuan, two 100-yuan notes and the rest in loose change.

Paragraph 27: The door opened and there stood the father, 300 yuan clenched tightly in hand.

Paragraph 29: On the seventh day of their son's death, the parents visited the shops and stalls, door after door, to pay back the 800 yuan they had borrowed from them.

Small numbers loom large when put into perspective. One can be quite certain that the 300-yuan loan that never had the chance to serve its purpose did not get mentioned so many times by chance. What the story loses by way of a mild breach of the journalistic writing conventions, it more than makes up with the shock value reified through repetition of vital facts and figures. The same was done to the fact that the three generations of the Cai family lived in two small flats, one rented in the faraway outskirts of town, one still under mortgage in the "low-end neighborhood".

Paragraph 3: Walking near the rented home in the village...

Paragraph 5: Returning to their rented home...

Paragraph 6: In this mortgaged flat of 75 square meters...

Paragraph 6: Changbai is the name of the village where the parents rented their home.

Paragraph 12: The place Mom and Pop rented is small and barely decorated.

Paragraph 21: The mortgaged flat is located on a street that was part of the lyrics in a pop song by a local singer.

Paragraph 22: The parents drew a meager monthly income. They chose to rent so as to save some money to help their son out.

Paragraph 30: Seeing that his condition stabilized, they returned to their rented flat.

As in the case of daily expenses (or the lack of which), poverty is an abstract notion until it is dragged down to real world referents and connected with bare necessities. Politically, the very existence of dire poverty and the concomitant sense of worthlessness after more than half a century of communist rule flies in the face of the dominant rhetoric. Internal contradictions within the system create dual images. The preaching of equalitarianism in the mass media has a street version that is filled with hardship and misery, where the "heroic" literally means overcoming everyday life [35].

\section{The everyday as the wrong side}

Prior to the reform era, it would have been absolutely unimaginable to encounter even the slightest suggestion that workers live in poverty and proletarians die without dignity in China's public sphere. The subject matter is freed up now and its status transformed from hidden to open discourse. However, connecting any social problem to a misguided ideology and a legitimacy crisis for the ruling authorities remains a taboo, which somehow explains the technique of repetition in the weightlifter story and its cleverness in ensuring what might be called "to insult without insulting."

Beyond the taboo, though, when one looks at the manifest core content type (egg yolk) and the deviant content type (egg shell), one notices an unmistakable wrestle between opposing sides of a negotiation, much like what Schor [36] observed on picturesque postcards of Paris at the turn of the $20^{\text {th }}$ century where she saw the unseen, assuming the forms of "a murmur of small voices speaking of minor aches and pains, long-awaited engagements, obscure family feuds; reporting on safe arrivals and unexpected delays...in short, carrying on the millions of minute transactions, the grain of everyday life".

The nuances of communication under scrutiny took place more than 100 years ago and surely, what people write on postcards today have since been colonized by "Paris-is-magnificent-wish-you-werehere" kind of strictly touristy blurbs, which is pleasant and consistent with the correct and more colorful other side. However, the nature of the contrasts between both sides of a Parisian postcard noted then still rings true in today's Chinese society when stigmas implied in "everydayness" and their system level antecedents are buried under layers of official discourse.

Next to boxing, acrobatics, and perhaps gymnastics, weightlifting is just about the cruelest thing parents could send their children into training for in their early childhood. The hero of our story had had two surgical operations done, one to his palm and one to his back, before he was old enough to compete. Common knowledge that cruel sports are for poor kids carries with it an expectedly heavy historical and cultural baggage in China. As unfortunate as it is true, the blue-collar class gravitates toward "low sports" because the ticket for entry is cheap in terms of demand for expensive equipment and expansive grounds. Those who are better off shun these sports because of high risks of selfinflicted injuries. People are constantly reminded of their deprivation both in absolute (poverty kills) and relative (feeling of denial of full citizenship) senses as part of the journey through everyday anxieties.

Paragraph 22: Cai Li could have lived. He keeps putting the trip to the 
hospital off because, in reality, he just does not have the money to receive medical attention... He is ashamed to ask for more from his parents.

In the text, the near total absence of pointing fingers at system flaws as the original sin for various frustrations of ordinary people is of course predestined given the imposition of self- or other-censorship in China's media system. If anything, however, what is missing only adds to the impact of symbolic contestations and works in effect to amplify, in the minds of readers, a hidden critique of the dominant ideology which by its own definition is meant to represent and favor the underprivileged and marginalized social groups.

All the people in the text, including those barely making a fleeting appearance, family members, neighbors, friends, relatives, peddlers, nurses, factory workers, live within the same confined space at the bottom of the social hierarchy. They share what Tang [35] described as the "collective desire to resist the inertia of everyday life", struggling more to survive than to thrive.

\section{Cultural norms as politicized site of contention}

The massive social renewal following the unleashing of market forces has breathed life into many cultural norms once crushed during the Mao era. Together with the reorientation of political attention away from class struggle and toward social harmony, a fresh trend of domestic commodification begins to offer therapy to people trapped in anxiety across all social strata with an emphasis on comfort and style [14].

Numerous traditional practices, rituals and ceremonies, superstitions, music and sports, aesthetic tastes in various aspects of life have been recovered, redesigned, and redefined to take on political meanings by association with group membership, official institutions, representatives of power, social status, and class identity. Food is one such thing and a big one at that, given China's nearly five thousand years of cuisine history. A recent TV documentary on traditional Chinese food, "China, on the tip of the tongue," broke all records on the ratings chart and raked in untold riches. In the literary report, food has a different kind, almost phantom like, presence and tells a sad story of its own.

Paragraph 3: Mom, cook me a couple of steamed buns with meat fillings..." (Mother's dream);

Paragraph 3: (The parents) got home and had some congee for breakfast;

Paragraph 6: The whole family started to eat, sliced potato with pepper, scrambled egg, fresh cucumber with soybean paste, and rice... (The wife) only had steamed buns;

Paragraph 8: (mother to father) Go ahead and buy four kilos of pork belly. I will make braised meat and zongzi (gluttonous rice wrapped in reed leafs, also known as Chinese tamale);

Paragraph 13: He didn't eat much of anything. Not even braised meat and zongzi could whet his appetite;

Paragraph 23: She was buying up the last few steamed buns in the shop...;

Paragraph 25: (The mother) bought two slices of watermelon, one bottle of water, and one bottle of orange juice;

Paragraph 28: He's too poor to afford meat. Once in a while, if they do manage to have some meat, the whole family will feel sick from not being used to meat in the stomach;
The writer seems obsessed with food and being specific about it. Apart from the definite imagery of poverty, food and meals are used here as a generic measure of culture, especially so in China where in many places people still greet one another with "have you had your meal?" What one eats, where one eats, who one eats with, who pays, how the food is prepared, who does the preparation are but some of the fundamental questions that place people "at the most rudimentary level, at the most necessary and the most unrespected level" [37]. The political meaning of culinary practices goes far beyond eating.

It is very hard to imagine that the Cai's would frequent restaurants or regularly entertain guests in their humble abode. For them, food is every bit an agent of social alienation as it is a cementing force of kindred ties at a time when communal and organic relations are no longer seen as relevant. In the nation's impatient push for modernity, food holds out against powerful tendencies and, through symbolic reconstructions by intellectuals and journalists, speaks up against official rhetoric about the indispensability of technology.

As readers dig deeper into the text, it becomes visible that aside from the socializing effects, some of the other common aspects of food also assume immediate cultural and political implications: traditional food of strong regional flavor (e.g., fresh cucumber dipped in soybean paste, potato, steamed buns with or without meat or vegetable fillings, etc.) which is large in portion but cheap in price still makes the staple on the daily menu; culinary joys even for women in the kitchen are out of question, so are nutritional considerations and dietary consciousness (e.g., fat meat is preferred over lean meat). Food for them is only to allay hunger instead of being something to experiment with, take pictures of, write about, and build social networks with. They are also the wrong kinds of people to have any meal expenses covered by the government.

\section{The same is true with all other daily expenditures}

Paragraph 9: Since he cannot claim reimbursement for anything, Cai never asks for receipt when taking a taxi, which makes it impossible to locate the first cab driver who took him to the hospital that day.

It is a cultural as well as political common sense in today's China that people who make a lot of money or are in positions of power actually spend very little, if at all, of their money, because they know how to milk the system to their best advantage. Sumptuous feasts, luxury hotels, planes and taxis are among some of the most typical institutionally refundable expenses. Compared with bribery of astronomical sums and grafts of a much more serious nature, these are petty corruptions. This relative pettiness of the sins seems to have absolved perpetrators of guilt, shame and blame. Although incidents of extravaganza by officials using public funds are quite often caught and exposed on mass media, talk of the rampancy with which they are taking place all over the country is prohibited in public discourse.

If the trouble of locating the first cab is the real concern, then the opening sentence of paragraph 9 could have been more straightforward and stated just the simple fact without the mention of reimbursement: Since Cai did not get a receipt for his taxi ride, it is now impossible to find the taxi driver. The allusion to corruption, tacitly made to look as a casual issue mentioned in passing, is a clear indication that cultural and political perceptions are mutually constituted.

At first glimpse, other references to cultural norms in the text appear to be less harmful: talk of death as taboo (paragraph 13); de factor job discrimination on account of obesity (paragraph 28); salary handed over to wife (paragraph 29); buying groceries on credit in local stores (paragraph 29), and so on. Almost anecdotal, surface aspects of 
culture sprinkle the text. The realness of the people (their needs and fears, their problems and limited means of solutions at their disposal) gives meaning to the notion of "lived culture" in Raymond Williams [38] early work.

The coexistence of culture in the streets of a little northeastern town and forms of its signification in films, poems, songs, and, for our purpose, news media poses a problem in which the former (life) has no choice but to be reduced to the terms of the latter (stories about life). The writer, however, makes an earnest attempt to break the mode and force into public discourse the widely shared discontent, resentment, disillusionment, and sheer boredom in the realm of hidden discourse through a tactical recourse to accepted rituals, traditions and cultural norms.

\section{Reasonable deductions as accepted practice of media professionalism}

Traditional definitions of objectivity in Western journalism emphasize an unambiguous separation of facts from opinions as the single most important basis for media professionalism. While they are imposed on hard news strictly, the restrictions are nearly completely relaxed for opinions and editorials even by the classical libertarian standard [39]. Literary journalism finds itself caught on both sides of such a functional segregation [40], at times telling the story as it "ought to be" and at times as it "is" mainly by means of reasonable deductions. For writers of reportage, investigative stories, features, or any other types of long-form journalism, the exercise of extrapolating facts into various interpretations leads to a thin isthmus of gray area between hidden and public discourse where facts are more than facts and opinions are less than opinions.

Still, in China, there is little doubt that journalists with strong left or right tendencies find the gray area advantageous to their ideological advocacies and an ideal site for planting counter frames and alternative frames. The writer of the weightlifter story is no exception:

Paragraph 2: Many signs show that for this unsophisticated, outgoing and jolly national champion, the last five years after his retirement had been the most depressing. Not only was he plagued by all kinds of pains and stubborn diseases that accompanied him in his entire sports career, he was also trapped in the mires of nitty gritty family disagreements, sudden reversal of status, general pressures of living. But a more fundamental source of depression came from the contrast of loneliness and noise between two places and two eras. It also came from the national sports system that he can never shake free from throughout his life.

In this passage, readers are introduced to a severe lashing out against individuals, families, institutions, social conditions, the system, and the changing times in which our hero is first invited and then forced into, missing nothing from the micro physiological and the psychology all the way to the macro sociological and political. To varying degrees, each of these contributed to the tragic undoing of the protagonist in its own intricate way. But at the most profound level, the grandeur overshadows the minute.

The nebulous notions of "two places and two eras" and the "national sports system" are deliberately kept in the cloud. No definitions or explanations are offered and no questions on "how" and why" are raised, much less answered. By the same token, the very last sentence is not elaborated and in fact never mentioned again in the rest of the story, leaving readers to wonder about what might have gone wrong in the national sports system that led to the hero's death.

Interestingly, everyone who is supposed to be puzzled seems to know the answers to the questions that are never raised: The system had squeezed the champion dry and dumped him. Two layers of reasonable deduction have occurred. The first is the connection between the champion's plight and the outside environment; the second, the connection in readers' mind between social problems and their systemic roots. By engaging in the politics of disguise, the writer demonstrates his savvy grasp of the rules of the game. He opens the floodgate of criticisms and a tirade of the necessary evils of the reform by making too obvious an attempt to close it.

Despite its value as an effective tool for discursive maneuvering in the Chinese political system, reasonable deduction is used rather economically in this story, with only two other occasions (one on what the hero was thinking and one on how he faced job discrimination). Consistent care can easily be detected in all other literary journalism pieces by the same author, suggesting a sober awareness that filling the space to the rim with oppositional messages, although the temptation for so doing is almost irresistible, could only backfire. At the time of the publication of this article, Southern Weekend had experienced no less than five rounds of editorial board reshuffling in less than 20 years after its launch. Clearly, the newspaper has its own glory-to-gloom story that matches that of the weightlifter.

\section{Conclusions}

In China, anyone could approach literary journalism like they would a fictional story, reading it just for the fun of it, without ever having to connect dots. As spectators, readers may find little mischiefs life has in stock for other people entertaining, although, we suspect, that may not be the case in the weightlifter story. The untold stories are too disturbing and the hushed tones too loud.

We start our theoretical queries with the distinct purpose of understanding how forbidden messages gain entry into public discourse through camouflaged narratives in China. Of particular interest is a content typology model we have advanced that dwells on structural invariance across cultural, political, and national boundaries but is free and open for variations in the content of text. We argue that mass media all over the world share common structural attributes (e.g., core, auxiliary, and alternative frames) that are relatively fixed in space and constant over time.

The universal nature of this framework makes it apt to say that the New York Times in America and the People's Daily in China are mirror images of each other. They are both restricted, quite statically, in their ideological obligations to promote the system which entails patriotism, national interest, members of the ruling body, family values, merit of religion, power of rituals, territorial integrity, foreign policy, domestic economy and all other bottom line, undisputable issues [41]. As part of their core message system, media in various socio-political ecologies are equally adamant about badmouthing their enemies and equally oblivious to their own application of double standards [42].

Public discourse has a deceptively high threshold, constructed and consolidated mainly by media's self-regulation, capable of weeding deviance or bringing dissent to its knees, as it were, in front of the desired line-to-take [28]. The dynamics of theorizing therefore is to be found in the random among the predictable, the incidental among the systematic, and the real among the make-believe.

These are the guiding principles for analysis before we dipped into the case study of the weightlifter story and found ourselves second guessing our way through a slow and gradual process of discovery. In what is termed unique reading in the literary criticism tradition, we looked, time and again, for compelling evidence and convincing 
Citation: Guo Z (2014) Advancing a Typology of Media Content: Analysis of a Literary Journalism Story. J Mass Communicat Journalism 5: 237. doi:10.4172/2165-7912.1000237

Page 7 of 8

substantiations for the claims that our hero had died in vain and that he inadvertently fell into the ranks of the "disposable people" as defined by his time, and was doomed to become a victim in a system supposedly erected in his interest and reinforced on his behalf.

Our model of media content typology foregrounds manifest content and latent content in public discourse as an arena in which the outer most fights the inner most, the alternative combats the core, and the David attacks the Goliath. Contrary to intuitive thinking, as space in the public discourse becomes more and more tolerant, deviant content expands rather than shrinks. To reiterate an earlier point, the temptation for blasphemy is too irresistible.

Clearly, in literary journalism, the relationship between narrative strategies actually employed and those that could be employed is analogous to the relationship between a particular tune and musical styles. While availability (of room for challenge) indeed generates adoption, our scrutiny of the text reveals a number of rhetorical tricks and a sharply focused target. The writer, as the above analyses show, devotes a lot of time to something to make it look as if he spent no time on it at all.

The techniques are nowhere near sophisticated: breach of journalistic writing norms, recoiling to the everyday, mixing cultural norms with political perceptions, and reliance on the comfort zone of reasonable deduction. The target is also direct: the system. Mind though that it is by no means certain whether the story is a loud cry for justice within existing social conditions and the political system or whether it is a denouncement of the system itself.

Words like "Communist party," "ideology," "politics," "reform," "leadership," "government," "commercialization," and "open policy" at the elevated abstract level and "fair treatment," "friendship," "care," "attention" at the mundane concrete level never made their way into the text. The series of unfortunate events simply unfolds in a neighborhood, a community, a society and a system shrouded in an unbearable atmosphere of unpleasantness.

At whatever level the conditions leading up to the death of the weightlifter are discussed and its aftermath analyzed, the most troublesome issue continues to be mind-boggling: Something is terribly wrong, but no one is to blame and, because of that, no one can be counted on for a solution, although, coming back to René Magritte's [43] words cited at the beginning of the paper, the visible is actually not present.

Which is precisely the point.

\section{Notes}

1. In a radio interview with Jean Neyens (1965) cited in Harry Torczyner (1977).

2. Honor-bound really, because the pressure to conform is found mainly within the editor or manager rather than without. To say that subtle ideological alignment is duty-bound is to emphasize the lack of alternatives and recognize the heavy role of institutional affiliations. In China today, even mandates from the Ministry of Information are sometimes ambiguous, making it certain, paradoxically enough, that there is room for editorial adjustment.

3. Clifford Geertz [44] in his now classic book on interpretation of cultures cited the example of differentiating a wink from similar but distinct acts (e.g., twitching of eyelids and mock wink etc.) and how an understanding of culture is thickly involved in the process.

\section{References}

1. Lee, Chin-chuan (2005) The conception of Chinese journalists: Ideological convergence and contestation. In Hugo de Burgh (ed.) Making Journalists: Diverse Models, Global Issues, London: Routledge.

2. Lull J (2013) China Turned On: Television, Reform, and Resistance. Routledge, Newyork.

3. McCormick, Barrett L (2003) Recent trends in mainland China's media: Political implications of commercialization. Issues and studies: a social science quarterly on China 38: 175-215.

4. Zhao Y (2001) Media and illusive democracy in China. The Public 8: 21-44.

5. Zhou H (2000) Chinese communist party press in a tug of war: A politicaleconomic analysis of the Shenzhen Special Zone Daily. Northwestern University Press, USA.

6. Lynch DC (1999) After the Propaganda State: Media, Politics, and "Thought Work" in Reformed China. Leland, CA: Stanford University Press.

7. Sun W (2010) Mission impossible: Soft power, communication capacity, and the globalization of Chinese media. International Journal of Communication 4: 54-72.

8. Winfield BH, Peng Z (2005) Market or party controls: Chinese media in transition. International Communication Gazette 67: 255-270.

9. Zhao Y (2000) from commercialization to conglomeration: The transformation of the Chinese press within the orbit of the party state. Journal of Communication 50: 3-26.

10. Chen X (2002) Occidentalism: A Theory of Counter-Discourse in Post-Mao China. (2edn), Rowman \& Littlefield.

11. Renwick Neil, Qing C (1999) China's political discourse towards the 21 century: Victimhood, identity, and political power. East Asia: An International Quarterly 17: 111-143.

12. Shirk, Susan (2010) Changing media, changing China. In Susan Shirk (Ed.) Changing Media, Changing China, London: Oxford University Press.

13. Guo Z (2001) To each according to its niche: Analyzing the political and economic origins for a structural segregation in Chinese press. Journal of Media Economics 14: 15-30.

14. Dirlik A, Zhang X (2000) Postmodernism and China. NC: Duke University Press, Durham, USA.

15. Chen Huailin, Lee, Chin-Chuan (1998). Press finance and economic reform in China. In Cheng J (Eds), China Review, Hong Kong: Chinese University Press.

16. Gramscian A (1989) Letters from Prison. Noonday Press, New York.

17. Dick H (1989) Subculture: The Meaning of Style. Routledge Londra

18. Meyer DS (1995) Framing national security: Elite public discourse on nuclear weapons during the cold war. Political Communication 12: 173-192.

19. Fang, YJ (2001) Reporting the same events? A critical analysis of Chinese print media tests. Discourse \& Society 12: 585-613.

20. Eliasoph $N$ (2009) Top-down civic projects are not grassroots associations: How the differences matter in everyday life. Voluntas: International Journal of Voluntary and Nonprofit Organizations 20: 291-308.

21. Shils, Edward (1983). Tradition. Chicago, IL: University of Chicago Press.

22. De Certeau M (1984) The Practice of Everyday Life. CA: University of California Press, Berkeley Los Angeles London.

23. Hsu Immanuel CY (2000) The Rise of Modern China (6thedn). Oxford University Press, London.

24. Hallin DC (1989) The "Uncensored War": The Media and Vietnam. Los Angeles, CA: University of California Press.

25. James S (1990) Domination and the Arts of Resistance: Hidden Transcripts. Yale University Press.

26. Goffman E (1959) The Presentation of Self in Everyday Life. Anchor Books, USA.

27. Moody $P$ (2001) The antipolitical tendency in contemporary Chinese political thinking. In Hua, Shiping (Eds) Chinese Political Culture (1989-2000), New York, NY: M. E. Sharpe. 
Citation: Guo Z (2014) Advancing a Typology of Media Content: Analysis of a Literary Journalism Story. J Mass Communicat Journalism 5: 237. doi:10.4172/2165-7912.1000237

Page 8 of 8

28. Herbert M (1964) One Dimensional Man. Beacon Press.

29. Lu, Xueyi (2002) Dangdai zhongguo shehui jieceng yanjiu baogao (A Report on Social Stratification in Contemporary China. Beijing: Social Sciences Press.

30. Steams PN (2001) Consumerism in World History: The Global Transformation of Desire. Routledge.

31. Foucault M (1977) Discipline and Punish: The Birth of the Prison. Vintage Books, New York, USA.

32. Foucault, Michel (1986) The Care of the Self. New York, NY: Vintage Books

33. Li, Haipeng (2013) Li Haipeng's blog.

34. Foucault M (1980) Power/Knowledge: Selected Interviews and Other Writings, 1972-1977. Pantheon Books, New York.

35. Tang X (2000) Chinese Modern: The Heroic and the Quotidian. Durham (N.C.), Duke University Press.

36. Schor N (1992) Cartes postales: Representing Paris 1900. Critical Inquiry, 18:188-244.
37. Giard, Luce (1980) Doing cooking. In Michel de Certeau, Luce Giard, \& Pierre Mayol (eds.) The Practice of Everyday Life 2: (152-159). Minneapolis, MINN: niversity of Minnesota Press.

38. Williams R (1958) Culture is ordinary. In Raymond Williams Resources of Hope: Culture, Democracy, Socialism, London: Verso.

39. Siebert, Fred, Peterson, Theodore, Schramm, et al. (1963) Four Theories of the Press: The Authoritarian, Libertarian, Social Responsibility and Soviet Communist Concepts of What the Press Should Be and Do. Urbana, IL: University of Illinois Press.

40. Schudson, Michael (1995) Discovering the News. New York, NY: Basic Books

41. Gouldner AW (1977) The Dialectic of Technology and Ideology. New York: The seabury press, The journal of politics $39: 513-514$.

42. Chomsky N (1989) Necessary Illusions: Thought Control in Democratic Societies. MASS: South End Press, Boston.

43. Magritte R, Torczyner H (1977) Magritte: Ideas and Images. H N. Abrams.

44. Geertz C (1973) The Interpretation of Cultures. Basic Books Classics, New York. 